\title{
Hypocretin-1 Modulates Rapid Eye Movement Sleep through Activation of Locus Coeruleus Neurons
}

\author{
Patrice Bourgin, ${ }^{1}$ Salvador Huitrón-Reséndiz, ${ }^{2}$ Avron D. Spier, ${ }^{1}$ Véronique Fabre, ${ }^{2}$ Beatriz Morte, ${ }^{1}$ \\ José R. Criado, ${ }^{2}$ J. Gregor Sutcliffe, ${ }^{1}$ Steven J. Henriksen, ${ }^{2}$ and Luis de Lecea ${ }^{1,2}$ \\ Departments of ${ }^{1}$ Molecular Biology and ${ }^{2}$ Neuropharmacology, The Scripps Research Institute, La Jolla, California 92037
}

\begin{abstract}
The hypocretins (hcrts), also known as orexins, are two recently identified excitatory neuropeptides that in rat are produced by $\sim 1200$ neurons whose cell bodies are located in the lateral hypothalamus. The hypocretins/orexins have been implicated in the regulation of rapid eye movement (REM) sleep and the pathophysiology of narcolepsy. In the present study, we investigated whether the locus coeruleus (LC), a structure receiving dense hcrtergic innervation, which is quiescent during REM sleep, might be a target for hort to regulate REM sleep. Local administration of hcrt1 but not hcrt2 in the LC suppressed REM sleep in a dose-dependent manner and increased wakefulness at the expense of deep, slow-wave sleep. These effects were blocked
\end{abstract}

with an antibody that neutralizes hort binding to hcrt receptor 1 . In situ hybridization and immunocytochemistry showed the presence of hcrt receptor 1 but not the presence of hcrt receptor 2 in the LC. Iontophoretic application of hcrt1 enhanced the firing rate of LC neurons in vivo, and local injection of hcrt1 into the LC induced the expression of c-fos in the LC area. We propose that hcrt receptor 1 in the LC is a key target for REM sleep regulation and might be involved in the pathophysiological mechanisms of narcolepsy.

Key words: norepinephrine; orexin; orexin receptors; c-fos; arousal; microinjection; immunocytochemistry
The hypocretins (hcrt1 and hcrt2), also called orexins, are two neuropeptides derived from the same precursor, which are expressed in a small set of neurons in the perifornical area of the hypothalamus (de Lecea et al., 1998; Sakurai et al., 1998). The hypocretins are neuroexcitatory (de Lecea et al., 1998; van den Pol et al., 1998) and bind to two different G-protein-coupled receptors, hcrt receptors 1 and 2 (hcrtr1 and hortr2, also known as OX1 and OX2 receptors) with different affinities (Sakurai et al., 1998). Recently, evidence has emerged that confirms a role for the hypocretins in arousal states. Lin et al. (1999) mapped the canine narcolepsy mutation (canarc-1) to hortr2. Knock-out experiments in mice demonstrated that the absence of hypocretin causes alterations in sleep architecture, particularly on the amount of rapid eye movement (REM) sleep during the dark period (Chemelli et al., 1999). In addition, hcrt-deficient mice display electroencephalographic patterns and behaviors that resemble those of narcoleptic attacks. Intracerebroventricular infusion of nanomolar amounts of hypocretin has recently been shown to increase arousal, reduce REM sleep, and affect neuroendocrine balance (Hagan et al., 1999). Nishino and colleagues (2000) found that seven of nine patients with narcolepsy had undetectable hcrt1 in CSF. These independent studies indicate that the hypocretins have a major role in the regulation of sleep, but the role of different brain structures and the contribution of each of the hcrt receptors remain unknown.

The projections of hcrt-containing neurons extend widely throughout the brain (Peyron et al., 1998; Date et al., 1999). Four main hcrtergic afferent regions can be recognized from anatomical studies (Peyron et al., 1998): an intrahypothalamic field; an ascending pathway through the basal ganglia, septum, and cerebral cortex; a medial pathway that connects a variety of thalamic nuclei; and a descending pathway that reaches the locus coeruleus (LC), dorsal

Received Feb. 4, 2000; revised July 28, 2000; accepted July 28, 2000.

This work was supported by National Institutes of Health Grants MH58543 (L.d.L.), GM32355 (J.G.S.), DA12669 (J.R.C.), and DA08301 (S.J.H.). P.B. was supported by Fondation Simone et Cino del Duca and Fondation Phillippe. B.M. was supported by a fellowship from Comunidad de Madrid. We thank Angels Almenar for help with immunofluorescence and Juliette Hinsche for technical assistance.

Correspondence should be addressed to Dr. Luis de Lecea, Department of Molecular Biology, MB-10, The Scripps Research Institute, 10550 North Torrey Pines Road, La Jolla, CA 92037. E-mail: 1lecea@scripps.edu.

Copyright (C) 2000 Society for Neuroscience $0270-6474 / 00 / 207760-06 \$ 15.00 / 0$ raphe, and spinal cord. These pathways are consistent with the expression patterns of hypocretin receptors 1 and 2 (Trivedi et al., 1998) and strongly suggest that the hypocretinergic system is involved in many different physiological functions, including feeding, blood pressure, hormone release, and arousal.

Neuroanatomical distribution of hort fibers suggest several brain regions relevant to the role of the hcrts in the regulation of the sleep-wakefulness cycle. Noradrenergic neurons in the LC are active during wakef ulness, decrease their activity during non-REM sleep, and are virtually silent during REM sleep (Hobson et al., 1975; Aston-Jones and Bloom, 1981). Because the LC receives the densest hcrtergic innervation, the purpose of the present study was to determine whether the LC is a physiological target for hert to regulate the sleep-wakefulness cycle and to assess the respective roles of the hcrtrs in arousal and sleep. We show that administration of hcrt1 to the LC dramatically decreases the amount of REM sleep. Moreover, injection of hcrt1 induced the expression of c-fos in the LC, and iontophoretic application enhanced the firing rate of LC neurons in vivo. Our results directly implicate hort1 and hortr1 in the modulation of REM sleep.

\section{MATERIALS AND METHODS}

Anatomical studies

Adult male Sprague Dawley rats (250-300 gm; $n=3$ ) were anesthetized with $\mathrm{CO}_{2}$, perfused intracardially with $4 \%$ paraformaldehyde in PBS, $\mathrm{pH}$ 7.4, and used for in situ hybridization and immunohistochemistry as previously described (de Lecea et al., 1997). For immunocytochemistry the following primary rabbit polyclonal antisera were used: 1:500 hort1 (Chemicon, Temecula, CA), 1:200 hortr2 (Santa Cruz Biotechnology, Santa Cruz, CA); 1:10,000 c-fos (Ab-5; Calbiochem, La Jolla, CA); and 1:400 tyrosine hydroxylase (TH) monoclonal (Chemicon). For double immunofluorescence, sections were incubated with Cy2-labeled antimouse $\mathrm{IgG}$ and rhodamine anti-rabbit $\mathrm{IgG}$, washed, and visualized under a Zeiss (Thornwood, NY) microscope using a $25 \times$ multi-immersion objective. Images were acquired with a charge-coupled device $1300 \mathrm{Y}$ camera (Roper Scientific) using IPLabs software and processed with Adobe (Mountain View, CA) Photoshop. For the c-fos immunocytochemistry, rats were injected with hort1 $(25 \mathrm{pmol})$ at noon and killed 60 min afterward. c-fos-positive cells were counted in five sections per animal ( $25 \mu \mathrm{m}$ thick) from three different animals.

In vivo experiments

Studies in freely moving animals. Experiments were performed on a total of 14 adult male rats (Sprague Dawley, 250-300 gm), kept under controlled 
environmental conditions $\left(12 \mathrm{hr}\right.$ light/dark cycle, $23 \pm 1^{\circ} \mathrm{C}$, and food and water ad libitum) and handled in agreement with the ethical rules for experimentation on laboratory animals (US Department of Health and Human Services publication 80-23; Office of Science and Health Reports, Division of Research Resources, National Institutes of Health, Bethesda, MD, 1980).

Rats $(n=14)$ were anesthetized under halothane (1-2\%) and implanted with electrodes for recording the electroencephalogram (EEG) and electromyogram. In addition, two stainless steel guide cannulas and a dummy stylus were stereotaxically implanted and positioned $3 \mathrm{~mm}$ above the right and left LC [Paxinos and Watson, 1986; from the ear bar zero: posterior $(\mathrm{P}),-0.8 \mathrm{~mm}$; lateral $(\mathrm{L}),+1.3 \mathrm{~mm}$; and $\mathrm{H},+2.3 \mathrm{~mm}$, using a posterior angle of $20^{\circ}$ from vertical]. After surgery, rats were allowed 7-10 d for recovery. All compounds were dissolved in saline. For intracerebral injections, a total volume of $0.2 \mu \mathrm{l}$ was injected through a smaller cannula $3 \mathrm{~mm}$ longer than the guide tube at the rate of $0.1 \mu \mathrm{l} / \mathrm{min}$, after which the cannula was left in place for another 2 min. Rats were injected bilaterally, except for one animal that was injected unilaterally. Infusion sites were verified histologically (frontal brain sections of $25 \mu \mathrm{m}$, cresyl violet and methylene blue staining). Polygraphic recordings and behavioral observation began immediately after the infusion for $5 \mathrm{hr}$ (12 P.M. to 5 P.M.). Recordings were performed after microinjection of saline for baseline, hcrt1 (2.5 and $25 \mathrm{pmol})$, hort2 (25 pmol), affinity-purified antisera $(1.4 \mathrm{mg} / \mathrm{ml})$, and hort1 $(25 \mathrm{pmol})$ preincubated with antiserum for $1 \mathrm{hr}$. Recordings were also performed on the day after a drug treatment after a sham microinjection to verify that the sleep and wakefulness amounts had returned to control values. Infusions of saline, hort1, hert2, and/or antiserum were given in random order. The hert peptides were obtained from Peninsula Laboratories (Belmont, CA) and the peptide synthesis core facility at The Scripps Research Institute.

Studies in halothane-anesthetized rats. Male Sprague Dawley rats (310$330 \mathrm{gm}$ ) were anesthetized with halothane $(3.0-4.0 \%)$ and placed into a stereotaxic apparatus. Body temperature was monitored and maintained at $37.0 \pm 0.1^{\circ} \mathrm{C}$ by a feedback-regulated heating pad. Halothane anesthesia was maintained at $0.75 \%$ after surgery. Extracellular potentials were recorded by a single $3.0 \mathrm{M} \mathrm{NaCl}$-filled micropipette $(5-10 \mathrm{M} \Omega, 1-2 \mu \mathrm{m}$ inner diameter) cemented $20-40 \mu \mathrm{m}$ distal to a four-barrel micropipette (30-80 $\mathrm{M} \Omega$ barrels), and amplified with an AXOPROBE-1A amplifier. Microelectrode assemblies were stereotaxically oriented into the LC [coordinates (from bregma): P, 12.35; L, 1.1; and ventral, 6.8-7.5, using a posterior angle of $20^{\circ}$ from vertical]. Single-unit activity was filtered at $1-3$ $\mathrm{kHz}(-3 \mathrm{~dB})$. Only spikes that had a $>3: 1$ signal-to-noise ratio were evaluated. Acquisition, analysis, and processing of data were performed by customized LabView software. Extracellularly recorded single-unit action potentials were discriminated temporospatially by a peak detector digitalprocessing algorithm.

\section{Statistical analysis}

Polygraphic recordings were analyzed visually every $15 \mathrm{sec}$ epoch into wakefulness (W), slow-wave sleep 1 (SWS1), SWS2, and REM sleep, according to standard criteria. Data were analyzed for 2 and $4 \mathrm{hr}$ periods and expressed as mean \pm SEM (total minutes per state per recording time). The following variables were examined: time spent in W, SWS1, SWS2, or REM sleep; duration and number of REM sleep episodes; and latency of SWS2 and REM sleep onset (interval between the time of injection and the first SWS2 or REM sleep episode of at least $15 \mathrm{sec}$ duration). The effects of hert1, hort2, antiserum, and antiserum and hert1 were analyzed by comparing sleep-wakefulness amounts after bilateral intra-LC administration of these compounds with those after administration of saline. A decrease in REM sleep duration of at least $75 \%$ of baseline (saline injection in the same rat) was considered a significant response. The $\chi^{2}$ test with the Yates correction for continuity was used to test the relationship between the injection site and the effect of hort1 on the sleep-wake cycle. Fisher's exact test (used because of low expected frequencies) and ANOVA were used to compare the number of responders to hert1 with the number of responders to hert2. Data from responder rats had the same profile and were pooled for statistical analysis. Grouped data were statistically compared by an ANOVA for comparison across collapsed groups of data, with $p<0.05$ as the critical limit. Comparisons among individual means were made by Fisher's least significant difference (LSD) post hoc test after ANOVA. The effect of hert1 on the firing rate of LC neurons was tested using the Wilcoxon matched pair test.

\section{Antibody blockade}

COS-7 cells, transiently transfected with human hcrtr1 cDNA (Receptor Biology), were diluted with growth medium (high-glucose DMEM and $10 \%$ fetal bovine serum) at a density of 50,000 cells per well. Cell culture medium was removed, and cells washed briefly in binding buffer $[10 \mathrm{~mm}$ HEPES, pH 7.4, $5 \mathrm{~mm} \mathrm{MgCl}, 1 \%$ BSA, and protease inhibitors $(50 \mu \mathrm{g} / \mathrm{ml}$ bacitracin, $50 \mu \mathrm{g} / \mathrm{ml}$ leupeptin, and $0.1 \mathrm{~mm}$ phenylmethylsulfonyl fluoride)]. Cells were incubated with a final concentration of $0.2 \mathrm{~nm}{ }^{125} \mathrm{I}$-hcrt1 (2200 Ci/mmol; New England Nuclear, Boston, MA) diluted in binding buffer for $45 \mathrm{~min}$ at room temperature. Nonspecific binding was defined by addition of $10 \mu \mathrm{M}$ unlabeled hert1. The anti-hcrt antiserum 2123 (Peyron et al., 1998) and a control antibody directed against preprohypocretin C-terminal peptide (de Lecea et al., 1998) were included in the binding
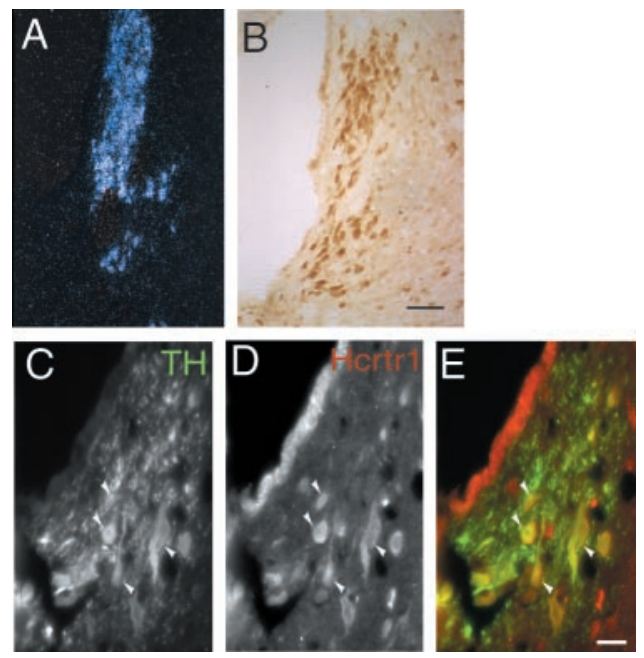

Figure 1. Localization of hertr1 in the LC. A, Dark-field photomicrograph of the LC hybridized with an hcrtr1 riboprobe. $B$, Immunocytochemical detection of hcrtr1. Note that most cells in the LC are labeled with the antibody. Scale bar, $50 \mu \mathrm{m}$. $C-E$, Immunofluorescence micrographs showing overlap (yellow, arrows) between hcrtr1-positive (red) and $\mathrm{TH}$ immunoreactive (green) neurons in the LC region. Scale bar, $25 \mu \mathrm{m}$.

reactions at various concentrations. The reactions were stopped by aspiration of the binding reaction mixture and two rapid washes with ice-cold wash buffer (HEPES, pH 7.4, and 1\% BSA). Cells were suspended in 150 $\mathrm{ml}$ of $0.2 \mathrm{M} \mathrm{HCl}$, and radioactivity was counted in a gamma counter.

\section{RESULTS}

\section{hcrtr1 immunoreactivity in the locus coeruleus}

The hypocretins/orexins exert their actions via binding to two G-protein-coupled receptors, hcrtr1 and hcrtr2. To determine whether hcrtrs were present in areas related to sleep modulation, we performed in situ hybridization and immunohistochemical staining of rat brain sections using antibodies specific to hertr1 and hertr2. Hcrtr1 mRNA is highly expressed in the LC (Fig. $1 A$ ), whereas hortr2 mRNA signals were not detected in this region (data not shown). Consistent with this result, hertr1 immunoreactivity was found in most if not all neurons in the LC (Fig. 1). hcrtr1immunoreactive cells co-localized with tyrosine hydroxylase-labeled neurons in the LC, indicating that hcrtr1 is expressed in the noradrenergic population of this nucleus (Fig. 1C). Adjacent nuclei, including the laterodorsal tegmental nucleus (LDT), and brainstem motor nuclei also contained immunoreactive cells positive for hcrtr1. The paraventricular nucleus of the hypothalamus, the medial thalamus, and layers II and III of the cerebral cortex also showed prominent immunoreactivity for hcrtr1. Staining was suppressed by preincubation with the peptide immunogen.

\section{hcrt1 administration in the LC affects sleep-wake cycle}

We tested the effects on the sleep-wake cycle of local bilateral application of hort1 and hort 2 to the LC area. To test the specificity of the site of injection, we mapped the injection sites histologically according to the atlas of Swanson (1992) (Fig. 2). A decrease in REM sleep duration with 25 pmol of hcrt1 superior to $75 \%$ of baseline (saline injection in the same rat) was considered a significant response. This criterion was chosen on the basis of our original hypothesis of a possible effect of hcrt1 on REM sleep. The number of responder rats in the group of animals injected in the LC (unilaterally or bilaterally) was statistically different from the number of responders in the group that received injections located outside the LC $\left(\chi^{2}=10.29 ; p<0.01\right)$.

From the responding animals, two rats received the injections in both LC regions; one animal received the injection in the LC area and subcoeruleus nucleus; another rat had the injection site in the LC and another site adjacent to LC; and two rats received the injection in only one LC side, and the other injection site was located outside the LC region. In one of these animals the LC 


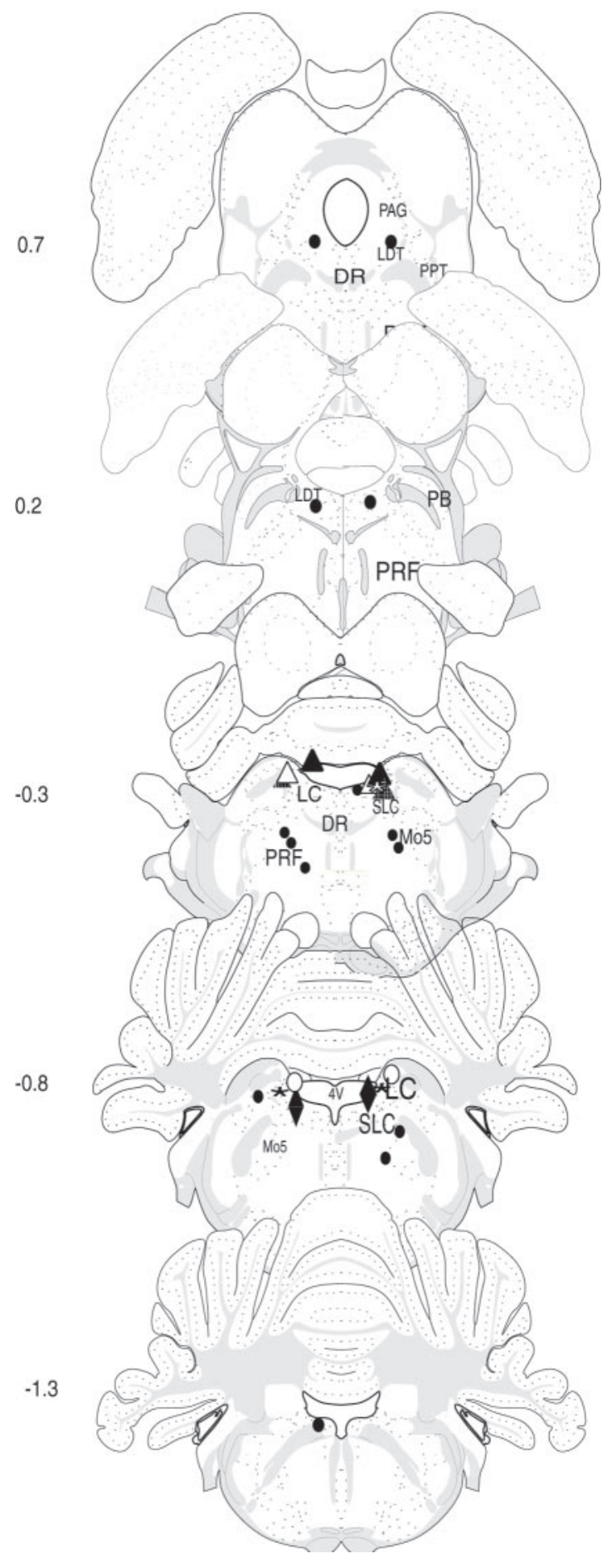

Figure 2. Schematic representation of hort injection sites. Drawings show coronal sections at five different levels of the brainstem (interaural, -1.3 to +0.7 ; Swanson, 1992). The black circles represent sites for which no changes in the sleep-wakefulness cycle were observed after injection. The triangles and diamonds correspond to the positive sites (at least one site is located in the LC) for which significant changes in W, SWS2, and REM sleep were observed after bilateral infusion of the $25 \mathrm{pmol}$ of hert1. For each rat the bilateral sites are represented by a triangle or a diamond and one color. One rat received unilateral injections (red triangle). Mo5, Motor trigeminal nucleus; $S L C$, subcoeruleus nucleus; $P R F$, pontine reticular formation; $P B$, parabrachial nucleus; $D R$, dorsal raphe; $P P T$, pedunculopontine tegmentum; $P A G$, periacqueductal central gray.

injection site was located in an area that overlaps both with the LC and the fourth ventricle. Another rat was injected in only one site corresponding to the right LC area (Fig. 2). In rats receiving hcrt1 in only one side, the effect profile on the sleep-wakefulness cycle was indistinguishable from that observed in rats injected bilaterally. In contrast, in nonresponding rats, injections were performed in the LDT or pontine reticular formation, outside the LC region $(n=7)$. In the same manner, injections located in the fourth ventricle (one site; $n=2$ ) were also negative for REM sleep blockade and wakefulness promotion.

Local administration of hert1 into the LC area produced significant changes in the amounts of REM sleep $\left(F_{(4,24)}=21.8 ; p<\right.$ $0.001), \operatorname{SWS} 2\left(F_{(4,24)}=8.4 ; p<0.001\right)$, and wakefulness $\left(F_{(4,24)}=\right.$ $16.9 ; p<0.001)$. In contrast, our data showed that hcrt1 had no effect on $\operatorname{SWS} 1\left(F_{(4,24)}=1.2 ; p>0.05\right)$. As shown in Figure 3, hert1 $(25 \mathrm{pmol})$ induced significant changes characterized by a decrease in REM sleep amounts $(-95 \%$ of control levels; $p<0.05$, Fisher's LSD post hoc comparisons) and SWS2 amounts $(-33 \% ; p<0.05$, Fisher's LSD) associated with an increase in wakefulness $(+62 \%$; $p<0.05$, Fisher's LSD) during the $0-4 \mathrm{hr}$ period after injection compared with baseline. A lower dose of hcrt1 (2.5 pmol) also induced a significant decrease in REM sleep compared with baseline $(p<0.05$, Fisher's LSD) but at a lower magnitude $(-31 \%$, Fisher's LSD) compared with the higher dose. However, the lower dose induced no significant changes in the amounts of SWS and wakefulness (Fig. 3B). All these effects were observed during $4 \mathrm{hr}$ of recording time and tended to recover by the fifth hour (Fig. $3 A$ ). No behavioral abnormalities were noticed in rats injected with hort1.

We then explored whether changes in the sleep-wake cycle produced by local application of hcrt1 into the LC area were equally distributed throughout the $4 \mathrm{hr}$ recording session (Table 1). Injection of 25 pmol of hert1 decreased the duration of SWS2 episodes $\left(F_{(1,14)}=5.9 ; p<0.05\right)$, increased the duration of W epochs during the first $2 \mathrm{hr}\left(F_{(1,14)}=4.9 ; p<0.05\right)$, and increased the number of $\mathrm{W}$ episodes during the $2-4 \mathrm{hr}$ interval $\left(F_{(1,14)}=4.6\right.$; $p=0.05)$. Changes in REM sleep were explained by a decrease in the number (hcrt1: 25 pmol, 14\%; 1-2 hr, $F_{(1,14)}=62.3 ; p<0.001$; $\left.2-4 \mathrm{hr}, F_{(1,14)}=21.4 ; p<0.001\right)$ and the duration (hcrt1: 25 pmol, $19 \% ; 1-2 \mathrm{hr}, F_{(1,14)}=86.1 ; p<0.001 ; 2-4 \mathrm{hr}, F_{(1,14)}=29.2 ; p<$ 0.001 ) of the REM sleep episodes. Latencies to SWS2 and REM sleep were also significantly increased after injection of 25 pmol of hort1 (SWS2, $F_{(1,16)}=18.9 ; p<0.001$; REM sleep, $F_{(1,16)}=31.7$; $p<0.001)$ compared with animals injected with saline (Table 1 ). Recordings after $4 \mathrm{hr}$ did not show significant changes compared with EEGs of control rats or with baseline EEGs. No significant changes in the duration of the vigilance states were observed after administration of $25 \mathrm{pmol}$ of hort 2 compared with saline (SWS, Fisher's LSD, $p>0.05$; REM sleep, Fisher's LSD, $p>0.05$; W, Fisher's LSD, $p>0.05 ; n=4)$, and the number of positive responses was significantly different from that of hcrt1 injection (Fisher's exact test, $p=0.014 ; n=4$ ).

\section{Antibody blockade}

In the search for reagents that would block hypocretin activity, we tested the ability of different antibodies to neutralize hort binding to cells transfected with hortr1. A concentration-dependent inhibition of ${ }^{125} \mathrm{I}$-hcrt1 binding to hertr1 expressed in COS7 cells by antibody 2123 was observed (data not shown). The control antibody did not appreciably decrease ${ }^{125}$ I-hcrt1 binding to hertr1. Antiserum alone did not modify the amounts of sleep and wakefulness when infused into the same site as hort1 $(n=2$; data not shown). However, preincubation of 25 pmol of hort1 with the antiserum completely prevented the promoting effect on W of hcrt1 as well as the decrease in SWS2 and REM sleep induced by hort1 infusion ( $n=4$; data not shown).

\section{Hypocretins are excitatory in the LC in vivo}

To determine whether the observed effect of hcrt1 was direct or, alternatively, through activation of neurons adjacent to the locus coeruleus, we applied the hcrt1 by iontophoresis in the LC and performed single-unit recordings in this region. Identification of LC neurons in vivo was done as previously described (Aston-Jones and Bloom, 1981; Harley and Sara, 1992). The mean frequency of 
A
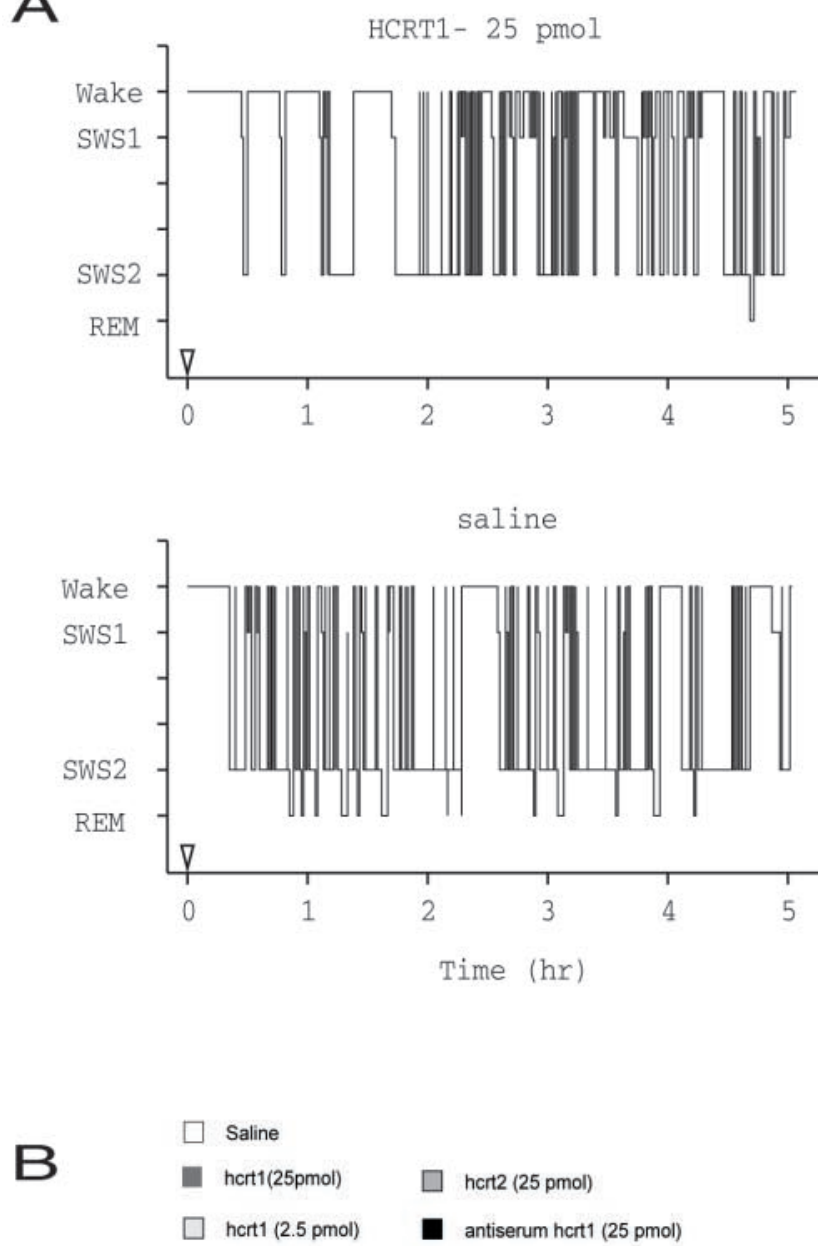

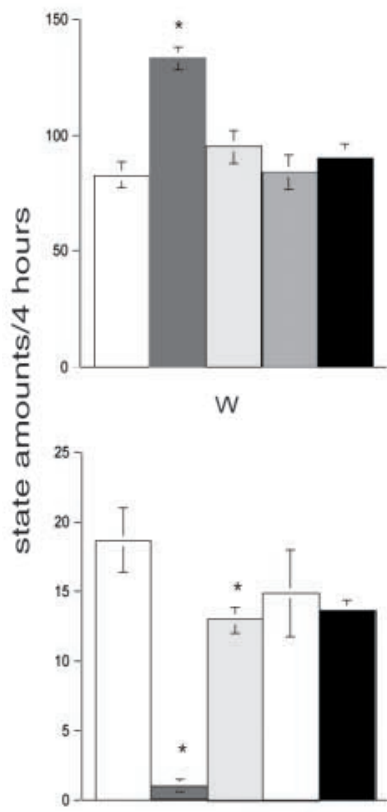

REM
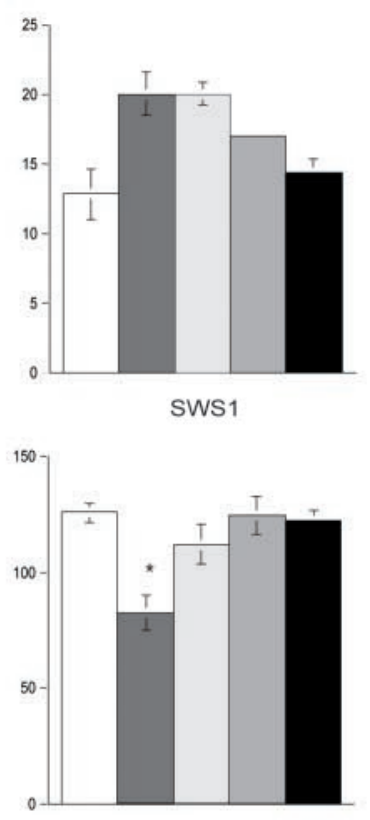

SWS2
Figure 3. Effects of hort1 and hort2 on the amounts of W, SWS1, SWS2, and REM sleep after microinjection into the LC. A, Bars represent the amounts of the states of vigilance (mean \pm SEM) expressed in minutes (saline, $n=7$; hert1, 25 pmol, $n=7$; hcrt1, 2.5 pmol, $n=5$; hert2, 25 pmol, $n=4$; hcrt1, $25 \mathrm{pmol}$, + antiserum, $n=4)$. *Significant difference $(p<$ 0.05 , Fisher's exact test) from baseline (rats treated with saline; open bars) $B$, Representative hypnographs obtained from one rat during $5 \mathrm{hr}$ after the infusion of the vehicle (bottom) and 25 pmol of hert1 (top) into the right LC. the firing rate of LC neurons was significantly increased by microiontophoretic application of hert1 ( -30 to $50 \mathrm{nA}$ ) from $2.95 \pm 0.22$ $\mathrm{Hz}$ during baseline recordings to $4.20 \pm 0.96 \mathrm{~Hz}$ (Wilcoxon matched pair test, $z=2.20 ; p=0.03 ; n=6$; Fig. 4).

\section{Hypocretins stimulate c-fos in the LC}

To determine the extent of neuronal activation on infusion of hcrt1 in the LC area, we used the immediate early gene product c-fos as an immunocytochemical marker. Rats were infused with saline $(n=5)$ and with hert1 $(n=6)$ and killed 60 min after the injection. c-fos-like immunoreactivity was observed in LC cells in animals treated with hcrt1, whereas little or no immunoreactivity in this area was observed after injection of saline (Fig. 5). The number of c-fos-positive cells was quantified in LC sections from three animals for each condition: $164 \pm 11 \mathrm{c}$-fos-positive cells were found in hcrt1-injected versus $31 \pm 13 \mathrm{c}$-fos-positive cells in saline-treated animals (Student's $t$ test, $p<0.01 ; n=3$ ). Only a few positive immunoreactive cells were observed in the cerebral cortex and hypothalamus.

\section{DISCUSSION}

The hypocretins have been implicated in a variety of physiological functions, including feeding (Sakurai et al., 1998), neuroendocrine regulation, and arousal (Chemelli et al., 1999; Hagan et al., 1999; Lin et al., 1999), as well as in the pathophysiology of narcolepsy. Here we have shown that administration of hort1 but not hort 2 to the LC has dramatic effects on sleep architecture. We have detected mRNA expression and immunoreactivity to hcrtr1, whereas neither mRNA nor protein expression for hcrtr2 was observed in the LC area. Finally, administration of hort1 increased the firing rate of LC neurons and induced c-fos in the LC area. These data strongly suggest that the alterations in sleep architecture induced by hcrt1 are the consequence of a neuroexcitatory effect on LC neurons through the hortr1.

hcrt1 application suppresses REM sleep and leads to a $70 \%$ increase in wakefulness and a $48 \%$ decrease in SWS2 after either unilateral or bilateral injections into the LC area. Bilateral injections in nearby structures had no effects on the sleep-wakefulness cycle, especially microinjections into the LDT, a cholinergic nucleus considered a "REM-on" structure that receives a relatively dense hcrtergic innervation. Injections into the pontine reticular formation, a nucleus that does not contain hcrt-immunopositive fibers (Peyron et al., 1998) and that is in close proximity to the "REM sleep induction zone" (Ahnaou et al., 1999; Kohlmeier and Reiner, 1999), did not show any effect. In contrast to published results (Hagan et al., 1999; Piper et al., 2000), local injections of the hcrts into the fourth ventricle (without any associated injection site located into the LC area) did not cause any significant effect on sleep-wakefulness cycle, presumably because the dose of the locally applied peptide was 100 times lower than the dose used for intracerebroventricular infusion. In addition, the observed effects were dose-dependent, indicating that the conditions used in the present study were not saturating. This, together with blockade of the effects on sleep and wakefulness by previous incubation with an anti-hcrt-specific antiserum, supports the specificity of hcrt-induced effects. It is noteworthy that injection of the lower dose of hcrt1 caused a selective reduction of REM sleep without significantly affecting other states of vigilance, which suggests that the physiological role of hcrt1 is mainly related to REM sleep, and that the alterations of the sleep-wake cycle seen at the higher dose are the result of overstimulation of LC noradrenergic cells.

LC neuronal activity is highly related to the status of wakefulness and REM sleep. It has been known for $>20$ years that monoaminergic neurons in the LC area are active during W, decrease their firing rate during SWS, and are virtually quiescent during REM sleep (Hobson et al., 1975; Aston-Jones and Bloom, 1981). Unilateral lesion of the LC in cats enhances REM sleep (Caballero and De Andres, 1986), and stimulation of cholinergic afferents promotes increased cortical desynchronization (Berridge and Foote, 1991), whereas 6-hydroxydopamine lesions do not cause 
Table 1. Sleep-wakefulness analysis of animals injected with hcrt1

\begin{tabular}{|c|c|c|c|c|c|c|c|}
\hline \multirow[b]{3}{*}{ Treatment } & & \multicolumn{6}{|l|}{ Latency } \\
\hline & & \multicolumn{3}{|l|}{$0-2 \mathrm{~h}$} & \multicolumn{3}{|l|}{$2-4 \mathrm{~h}$} \\
\hline & & Time & $n$ & Duration & Time & $n$ & Duration \\
\hline \multicolumn{8}{|l|}{ Wakefulness } \\
\hline $\begin{array}{l}\text { Saline } \\
\text { hcrt } 1 \text { ( } 25\end{array}$ & & $49.8 \pm 5.6$ & $19.1 \pm 2.4$ & $2.9 \pm 0.6$ & $32.9 \pm 2.4$ & $24.5 \pm 2.7$ & $1.5 \pm 0.2$ \\
\hline pmol) & & $85.1 \pm 3.5^{*}$ & $18.2 \pm 2.3$ & $5.5 \pm 0.9^{*}$ & $51.3 \pm 5.9^{*}$ & $34.4 \pm 3.4^{*}$ & $1.6 \pm 0.2$ \\
\hline \multicolumn{8}{|l|}{ SWS 1} \\
\hline $\begin{array}{l}\text { Saline } \\
\text { hcrt } 1 \text { ( } 25\end{array}$ & & $5.9 \pm 0.4$ & $7.4 \pm 0.8$ & $0.8 \pm 0.06$ & $6.9 \pm 1.0$ & $7.3 \pm 0.9$ & $0.9 \pm 0.08$ \\
\hline pmol) & & $7.9 \pm 1.3$ & $9.2 \pm 1.4$ & $0.8 \pm 0.07$ & $12.0 \pm 2.3$ & $14.3 \pm 2.4^{*}$ & $0.8 \pm 0.04$ \\
\hline \multicolumn{8}{|l|}{ SWS 2} \\
\hline $\begin{array}{l}\text { Saline } \\
\text { hort } 1(25\end{array}$ & $24.5 \pm 4.4$ & $55.9 \pm 4.4$ & $18.1 \pm 2.4$ & $3.3 \pm 0.5$ & $69.9 \pm 2.3$ & $23.4 \pm 2.0$ & $3.1 \pm 0.2$ \\
\hline pmol) & $52.9 \pm 4.6^{*}$ & $26.9 \pm 3.2^{*}$ & $14.4 \pm 1.8$ & $2.0 \pm 0.3^{*}$ & $55.7 \pm 7.0$ & $30.0 \pm 2.9$ & $2.0 \pm 0.4^{*}$ \\
\hline \multicolumn{8}{|l|}{ REM } \\
\hline $\begin{array}{l}\text { Saline } \\
\text { hort } 1(25\end{array}$ & $50 \pm 6.3$ & $8.4 \pm 1.7$ & $6 \pm 0.8$ & $1.3 \pm 0.2$ & $10.2 \pm 1.1$ & $6.4 \pm 1.0$ & $1.7 \pm 0.1$ \\
\hline pmol) & $209.5 \pm 24.6^{*}$ & $0.05 \pm 0.03^{*}$ & $0.2 \pm 0.1^{*}$ & $0.05 \pm 0.04^{*}$ & $0.9 \pm 0.4^{*}$ & $1.4 \pm 0.6^{*}$ & $0.3 \pm 0.2^{*}$ \\
\hline
\end{tabular}

Latency, mean duration, and total time are expressed in minutes \pm SEM. Seven animals were analyzed per condition, for 2 hr periods.

*Statistical significance of Fisher's exact test $(p<0.05)$.

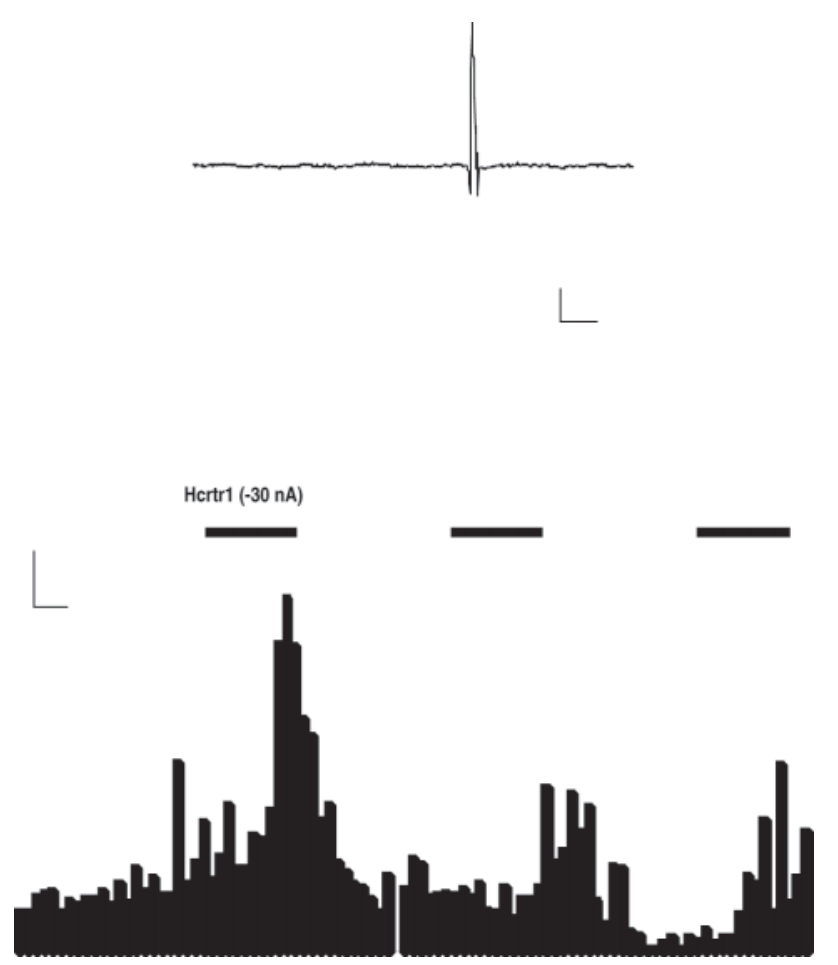

Figure 4. Activation of hypocretin 1 receptors increases the firing rate of locus coeruleus neurons. Top tracing, Filtered recorded signal demonstrating the waveforms of the action potential. Calibration: $100 \mu \mathrm{V}, 5 \mathrm{msec}$. Bottom, Rate meter record demonstrating that in situ microelectrophoretic application of hypocretin $1(1 \mathrm{mg} / \mathrm{ml})$ produced a marked activation of a spontaneously active LC neuron. Calibration: $5 \mathrm{~Hz}, 5 \mathrm{sec}$.

changes in the behavioral state but affect immediate early gene expression in the cortex (Cirelli et al., 1996). Although interpretation of these data is difficult because of the complexity of the neuroanatomical distribution of neurons in this area, the LC is currently regarded, in part, as a "REM-off" structure in the proposed model of reciprocal interaction of REM sleep regulation (Hobson et al., 1975). Thus, our results directly implicate the
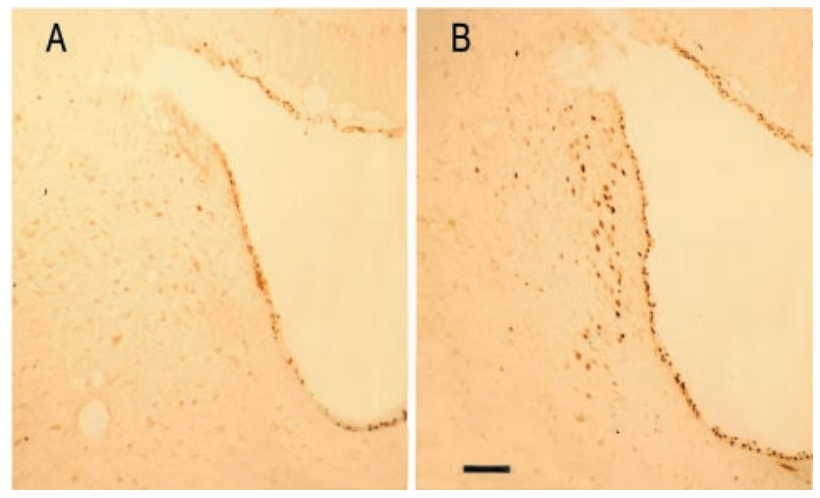

Figure 5. Injection of hert1 stimulates c-fos immunoreactivity in the LC. Photomicrographs show c-fos immunoreactivity in the LC area after injection of saline $(A)$ or iontophoretic administration of hcrt1 $(B)$. Scale bar, $100 \mu \mathrm{m}$.

hcrtergic system on the regulation of the wakefulness cycle by the LC. Considering that the raphe nucleus, another REM-off area, also receives hcrt innervation and expresses hcrt receptors (Trivedi et al., 1998), further experiments are needed to determine the role of the hcrts in REM sleep regulation in other brainstem nuclei.

The hypocretins are excitatory in the hypothalamus and spinal cord (de Lecea et al., 1998; van den Pol, 1999). Here we have shown that in vivo administration of hcrt1 increases activity of LC neurons. This is consistent with recent data showing an effect of hort1 (Hagan et al., 1999; Horvath et al., 1999) on LC slices in vitro and with data demonstrating that mild electrical stimulation of the LC suppresses REM sleep (Singh and Mallick, 1996). However, in contrast to a previous study describing stimulation of LC neurons in vitro by hert2 (Horvath et al., 1999), we did not observe physiological responses to $\mathrm{LC}$ administration of hcrt2. Because the in vitro assay was done in saturating concentrations of the peptide, the excitatory effect of hort 2 on LC slices may be mediated through hortr1.

The excitatory effect of hcrt1 raises the question of which cell type is activated in the LC area. Increased cell firing reported in this study may be assigned to noradrenergic cells because of their predominant distribution within this area and their electrophysio- 
logical firing pattern. Also, TH mRNA and norepinephrine concentration are increased in the LC after $72 \mathrm{hr}$ of REM sleep deprivation (Porkka-Heiskanen et al., 1995), and the percentage of REM sleep negatively correlates with noradrenergic (NA) c-fospositive cells (Maloney et al., 1999). Moreover, studies in cats have recently shown that norepinephrine application on peri-LC $\alpha$, an area next to the LC, suppresses REM sleep with an increase in W and a decrease in SWS (Crochet and Sakai, 1999). Despite the large amount of data implicating NA cells in the modulation of REM sleep, it is possible that hcrt1 stimulates cholinergic cells in the area, which are also known to promote wakefulness. Indeed, cholinergic and noradrenergic cells are in close proximity in the LC area and are critical for wakefulness promotion. However, generation of the state of REM sleep may depend on the cessation of NA LC neurons and simultaneous activation of cholinergic neighboring neurons (Jones, 1991). Thus, it is likely that the REM suppressor effect of hcrt1 reported here is the consequence of a stimulation of NA cells in the LC area and not of a stimulation of cholinergic cells. Moreover, our data showing TH staining of hcrtr1-positive cells support the idea that the observed effects are attributable to activation of NA neurons.

Interestingly, the effects of hort1 reported here are reciprocal to those observed in hcrt/orexin knock-out mice (Chemelli et al., 1999), in which REM and SW sleep are increased during the dark period, whereas wakefulness is decreased. The observed phenotype of hort deficiency could be explained by lack of hcrtergic activation of LC neurons and suggests that the LC area is a key target for the hcrts to regulate the sleep-wakefulness cycle. LC neurons cease to fire during cataplexy (Wu et al., 1999), suggesting that the signaling mechanisms in LC neurons are impaired in narcolepsy. Narcoleptic patients show a dramatic increase in sleep fragmentation, although sleep homoeostasis is relatively well preserved during the dark period (Nishino and Mignot, 1997). Thus, horts might be required to modulate the firing of REM-off neurons in the brainstem and to stabilize sleep transitions. Absence of hort signaling in narcolepsy may thus result in disregulation of the mechanism that establishes boundaries between sleep states.

The lack of effect of hort 2 administration in the LC area and the absence of hcrtr2 immunoreactivity or hybridization signals strongly suggest that hcrt1 regulates REM sleep through interaction with hcrtr1. The role of hertr2, which has been shown to be responsible for canine narcolepsy and is not expressed in the LC in rats, remains to be determined. Also, this raises the question of the possible relationship between hortr1 and human narcolepsy. Further studies will be required to assess the roles of the hort receptors and the brain regions involved in different components of the disease (i.e., cataplexy, sleep fragmentation, and REM sleep attacks).

Together, our data indicate that hort1 in the LC area modulates REM sleep by acting on the firing rate of noradrenergic neurons through hcrtr1 receptors and suggest that the LC is a key target of the hcrtergic system for sleep-wakefulness cycle regulation. However, the possible implication of hcrtergic transmission within the LC area in the pathophysiological mechanisms of human narcolepsy remains to be explored.

\section{REFERENCES}

Ahnaou A, Basille M, Gonzalez B, Vaudry H, Hamon M, Adrien J, Bourgin P (1999) Long-term enhancement of REM sleep by the pituitary adenylyl cyclase-activating polypeptide (PACAP) in the pontine reticular formation of the rat. Eur J Neurosci 11:4051-4058.

Aston-Jones G, Bloom FE (1981) Activity of norepinephrine-containing locus coeruleus neurons in behaving rats anticipates fluctuations in the sleep-waking cycle. J Neurosci 1:876-886.

Berridge CW, Foote SL (1991) Effects of locus coeruleus activation on electroencephalographic activity in neocortex and hippocampus. J Neurosci 11:3135-3145.

Caballero A, De Andres I (1986) Unilateral lesions in locus coeruleus area enhance paradoxical sleep. Electroencephalogr Clin Neurophysiol 64:339-346.

Chemelli RM, Willie JT, Sinton CM, Elmquist JK, Scammell T, Lee C, Richardson JA, Williams SC, Xiong Y, Kisanuki Y, Fitch TE, Nakazato M, Hammer RE, Saper CB, Yanagisawa M (1999) Narcolepsy in orexin knockout mice: molecular genetics of sleep regulation. Cell 98:437-451.
Cirelli C, Pompeiano M, Tononi G (1996) Neuronal gene expression in the waking state: a role for the locus coeruleus. Science 274:1211-1215.

Crochet S, Sakai K (1999) Effects of microdialysis application of monoamines on the EEG and behavioural states in the cat mesopontine tegmentum. Eur J Neurosci 11:3738-3752.

Date Y, Ueta Y, Yamashita H, Yamaguchi H, Matsukura S, Kangawa K, Sakurai T, Yanagisawa M, Nakazato M (1999) Orexins, orexigenic hypothalamic peptides, interact with autonomic, neuroendocrine and neuroregulatory systems. Proc Natl Acad Sci USA 96:748-753.

de Lecea L, del Rio JA, Criado JR, Alcantara S, Morales M, Henriksen SJ, Soriano E, Sutcliffe JG (1997) Cortistatin is expressed in a distinct subset of cortical interneurons. J Neurosci 17:5868-5880.

de Lecea L, Kilduff TS, Peyron C, Gao X, Foye PE, Danielson PE, Fukuhara C, Battenberg EL, Gautvik VT, Bartlett II FS, Frankel WN, van den Pol AN, Bloom FE, Gautvik KM, Sutcliffe JG (1998) The hypocretins: hypothalamus-specific peptides with neuroexcitatory activity. Proc Natl Acad Sci USA 95:322-327.

Hagan JJ, Leslie RA, Patel S, Evans ML, Wattam TA, Holmes S, Benham CD, Taylor SG, Routledge C, Hemmati P, Munton RP, Ashmeade TE, Shah AS, Hatcher JP, Hatcher PD, Jones DN, Smith MI, Piper DC, Hunter AJ, Porter RA, Upton N (1999) Orexin A activates locus coeruleus cell firing and increases arousal in the rat. Proc Natl Acad Sci USA 96:10911-10916.

Harley CW, Sara SJ (1992) Locus coeruleus bursts induced by glutamate trigger delayed perforant path spike amplitude potentiation in the dentate gyrus. Exp Brain Res 89:581-587.

Hobson JA, McCarley RW, Wyzinski PW (1975) Sleep cycle oscillation: reciprocal discharge by two brainstem neuronal groups. Science 189:55-58

Horvath TL, Peyron C, Diano S, Ivanov A, Aston-Jones G, Kilduff TS, van Den Pol AN (1999) Hypocretin (orexin) activation and synaptic innervation of the locus coeruleus noradrenergic system. J Comp Neurol 415:145-159.

Jones BE (1991) The role of noradrenergic locus coeruleus neurons and neighboring cholinergic neurons of the pontomesencephalic tegmentum in sleep-wake states. Prog Brain Res 88:533-543.

Kohlmeier KA, Reiner PB (1999) Vasoactive intestinal polypeptide excites medial pontine reticular formation neurons in the brainstem rapid eye movement sleep-induction zone. J Neurosci 19:4073-4081.

Lin L, Faraco J, Li R, Kadotani H, Rogers W, Lin X, Qiu X, de Jong PJ, Nishino S, Mignot E (1999) The sleep disorder canine narcolepsy is caused by a mutation in the hypocretin (orexin) receptor 2 gene. Cell 98:365-376.

Maloney KJ, Mainville L, Jones BE (1999) Differential c-Fos expression in cholinergic, monoaminergic, and GABAergic cell groups of the pontomesencephalic tegmentum after paradoxical sleep deprivation and recovery. J Neurosci 19:3057-3072.

Nishino S, Mignot E (1997) Pharmacological aspects of human and canine narcolepsy. Prog Neurobiol 52:27-78.

Nishino S, Ripley B, Overeem S, Lammers GJ, Mignot E (2000) Hypocretin (orexin) deficiency in human narcolepsy Lancet 355:39-40.

Paxinos G, Watson C (1986) The rat brain in stereotaxic coordinates. New York, Academic.

Peyron C, Tighe DK, van den Pol AN, de Lecea L, Heller HC, Sutcliffe JG, Kilduff TS (1998) Neurons containing hypocretin (orexin) project to multiple neuronal systems. J Neurosci 18:9996-10015.

Piper DC, Upton N, Smith MI, Hunter AJ (2000) The novel brain neuropeptide, orexin-A, modulates the sleep-wake cycle of rats. Eur J Neurosci 12:726-730.

Porkka-Heiskanen T, Smith SE, Taira T, Urban JH, Levine JE, Turek FW, Stenberg D (1995) Noradrenergic activity in rat brain during rapid eye movement sleep deprivation and rebound sleep. Am J Physiol 268:R1456-R1463.

Sakurai T, Amemiya A, Ishii M, Matsuzaki I, Chemelli RM, Tanaka H, Williams SC, Richardson JA, Kozlowski GP, Wilson S, Arch JR, Buckingham RE, Haynes AC, Carr SA, Annan RS, McNulty DE, Liu WS, Terrett JA, Elshourbagy NA, Bergsma DJ, Yanagisawa M (1998) Orexins and orexin receptors: a family of hypothalamic neuropeptides and $G$ protein-coupled receptors that regulate feeding behavior. Cell 92:573-585.

Singh S, Mallick BN (1996) Mild electrical stimulation of pontine tegmentum around locus coeruleus reduces rapid eye movement sleep in rats. Neurosci Res 24:227-235.

Swanson LW (1992) Brain maps: structure of the rat brain. New York, Elsevier.

Trivedi P, Yu H, MacNeil DJ, Van der Ploeg LH, Guan XM (1998) Distribution of orexin receptor mRNA in the rat brain. FEBS Lett 438:71-75.

van den Pol AN (1999) Hypothalamic hypocretin (orexin): robust innervation of the spinal cord. J Neurosci 19:3171-3182.

van den Pol AN, Gao XB, Obrietan K, Kilduff TS, Belousov AB (1998) Presynaptic and postsynaptic actions and modulation of neuroendocrine neurons by a new hypothalamic peptide, hypocretin/orexin. J Neurosci 18:7962-7971.

Wu MF, Gulyani SA, Yau E, Mignot E, Phan B, Siegel JM (1999) Locus coeruleus neurons: cessation of activity during cataplexy. Neuroscience 91:1389-1399. 